BMC JOURNAL OF SCIENTIFIC RESEARCH
A Multidisciplinary Peer Reviewed Research Journal
ISSN: 2594-3421 (Print), 2773-8191 (Online)

\title{
Distribution of Bombus haemorrhoidalis Smith and its Interrelationship with Host Plants in Chitwan Annapurna Landscape of Central Nepal \\ Kishor Chandra Ghimire ${ }^{1}$, Daya Ram Bhusal ${ }^{*}$ \\ E-mail: kishor.745713@cdz.tu.edu.np \\ Received: Oct. 5, 2021, Accepted: Dec. 15, 2021
}

\begin{abstract}
Occurrence and variety of flowering host plant of native Bombus pollinators are viewed as basic alternatives than the imported species. The use of native bumblebee species for pollination was considered more significant than imported bumblebees to reduce environmental impact and pest problems. B. haemorrhoidalis is the most dominant species of Chitwan Annapurna Landscape in agricultural and wild flora during April to September 2019. We followed assessable walking trails and used insect net for sample collection. The effect of different environmental variables on the floral host plant resources of this native bumblebee was examined. With eight locations ranging from 1407 to 2506 meters above sea level, twenty-seven species of seventeen plant families were identified as pollen and nectar foraging host plants. B haemorrhidalis distribution frequency is correlated with relative humidity (0.07438968) and altitude (0.495657857). The most visited plant family was Balsaminaceae and plant was Imatian scrabida. This study gives the knowledge of abundance of host plants, ecological and biological relationship of the B. haemorrhoidalis in Nepal.
\end{abstract}

Keywords: bumblebees, foraging, host, pollinator, pant families, species

\section{Introduction}

Bumblebees (Hymenoptera, Apidae) are pollinators of many wild as well as agricultural plants. They have high thermoregulatory behavior. Rapid pollination, burst the pollen sac by vibrating the wings and ability to forage at low ambient temperature (MillerStruttmann et al., 2014) and light makes them the most consistent and efficient pollinators (Heinrich, 1979; Abrol, 2012). So, they behave as significant pollinators, mainly in an alpine surroundings (Yu et al., 2012), gradually, accelerated world human population stresses the usage of such crop pollinators specifically for commercial plants grown under extensive (Griffiths and Robberts, 1996). Pollination by these important actors' aids in fruit production, weight, size, and other chemical characteristics to achieve costeffective production (Aizen et al., 2008; Klein et al., 2007).

Different species bumblebees like Bombus terrestris, B. impatiens, B. occidentalis and a number of other are used for commercial pollination of various crops within the world (Kwon and Saeed, 2003; Velthuis and van Doorn, 2006). These species are expensive to import (Velthuis and van Doorn, 2006), and they compete for nesting locations, food,

$1 \mathrm{Mr}$. Ghimire is Assistant Professor in Zoology at Birendra Multiple Campus (Tribhuvan University) $1 *$ Dr. Bhusal is Associate Professor in Zoology at Central Department of Zoology (Tribhuvan University) 
and other resources with native pollinator species, particularly Bombus (Couvillon et al., 2010).

34 species of bumblebees have been recorded from Nepal (William et al., 2010). Among them, $B$. haemorrhoidalis is a dominant pollinator of wild as well as agricultural flowers in the lower to mid altitude region of mid himalya (William 2010 and Streinzer M., et al., 2019) and it is the major pollinator in commercial farm of cardamom (Sinu et al 2007). Fourteen CHAL species of plants have been classified in the CITES Annexes, and their extinction is due to a variety of factors, one of whom is reproductive success. Plant reproductive success has diminished due to the decline of suitable pollinators. However, no research has been done on the interaction between pollinators and hostplants, that results in a decline in plant reproductive rate due to a shortage of adequate pollinators. This study fills a knowledge gap in CHAL on the abundance of $B$ haemorrhoidalis and their forage plants at various elevation levels.

\section{Materials and Methods}

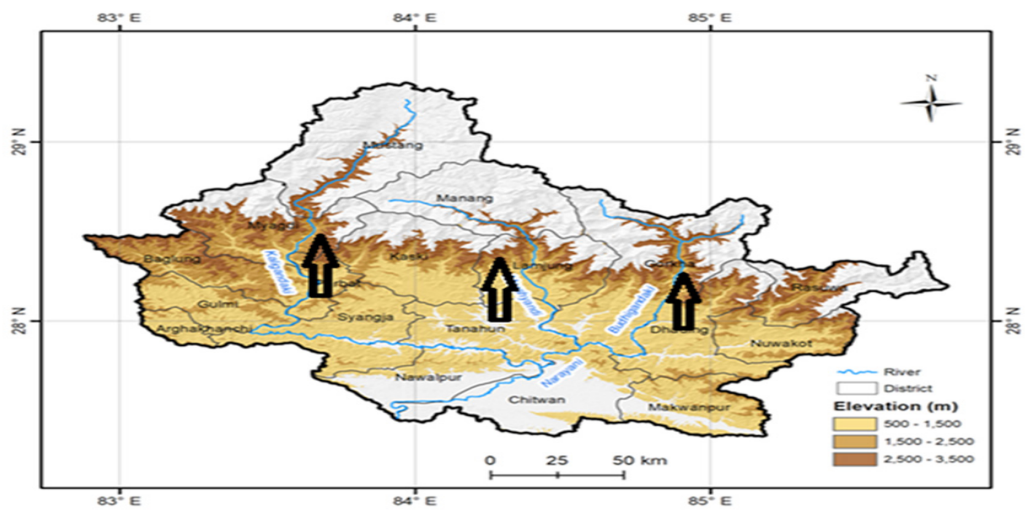

Fig: 1- study area

Surveys were conducted along an altitudinal gradient (from 500 to $3500 \mathrm{~m}$ asl) in three river valleys of the Chitwan Annapurna Landscape (CHAL) Kaligandaki (west site), Marsyangdi (mid site), and Budhigandaki (east site) in central Nepal (Figure 1) throughout flowering season between April and November 2019 at 9 am to $6 \mathrm{pm}$. We observed around the flowering plants present at any location along the walking path when a foraging bumblebee was noticed, and the bumblebees on the site were collected and recorded. An entomological net was used to capture Bombus species, which were then killed with ethyl acetate. We noted habitat types, altitude, and the GPS position of the collecting points during the survey. To prevent mold growth during shipment, specimens were kept in airtight containers with a few sheets of tissue paper and a drops of ethyl alcohol and were subsequently dry-mounted using standard insect pins. The collected specimens were deposited in the Entomological Museum of the Central Department of Zoology, Tribhuvan University, Kirtipur (www.cdztu.edu.np). The Collected specimens were observed under a stereoscopic microscope and identified 
using published keys for adjoining regions, eg. Nepal (William 2010), North China (An et al 2014), India (Saini et al 2015), Kashmir (Williams 1991) and Sichuan (Williams et al 2009).

\section{Results}

Collected 103 specimens of $B$. haemorrhoidalis showed wide range of variations providing the successful adaptation in the nature. It was found in agricultural and natural mountainous landscape between 1407 and 2505 meters in altitude. Grassland, home gardens, dense forest trees, and cultivated crops were among their preferred forage plants. The distribution frequency of $B$. haemorrhoidalis was highest in lower altitudes and low in high altitudes (Fig 3). This species was not recorded highest altitude of the 2505 masl in our study areas. During our field, 40\% specimens were recorded from agricultural land, $31 \%$ from forest, $25 \%$ from grass land and $4 \%$ from home garden (fig. 2)

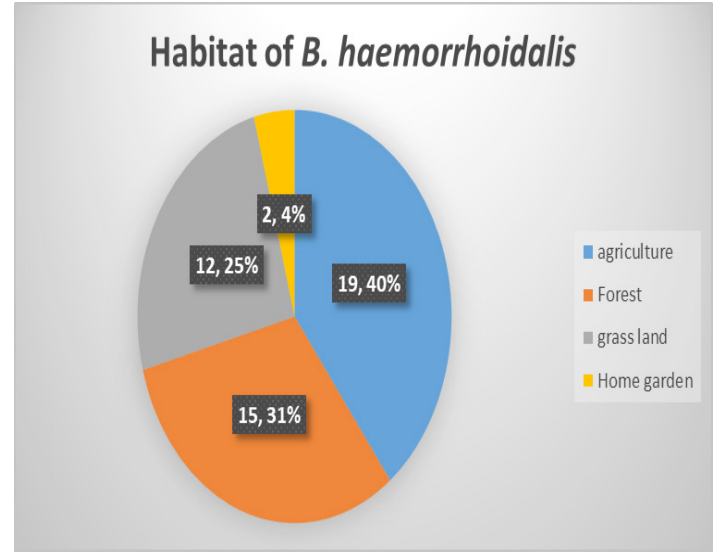

Fig: 2 Habitat distribution

\section{Altitudnal wise abundance of \\ B. haemorrhoidalis}

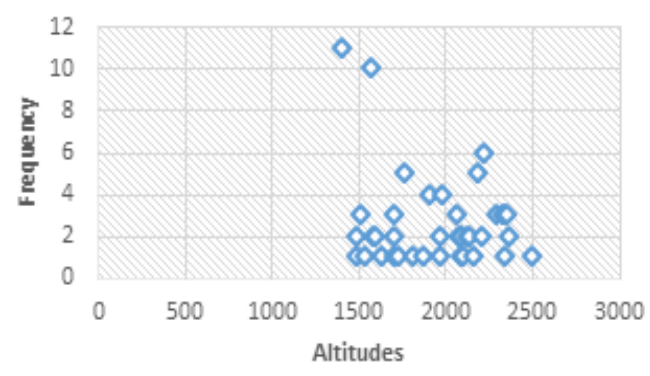

Fig: 3 Altitudinal distribution

The correlation between frequency of B. haemorrhoidalis with environmental variables (temperature and relative humidity) and altitude was calculated, we obtained (Relative humidity $=0.07438968)$, $($ Temperature $=-0.193060815)$ and altitude (Altitude $=$ 0.495657857 ). Then, we concluded that frequency of B haemorrhoidalis was negatively correlated with relative temperature but positively correlated with altitude and humidity. Twenty-six species belonging to seventeen plant families were observed as host plants in eight new habitat ranging from 1407-2505 $\mathrm{m}$ altitude (Fig 4 and 5).

The families of plants visited for nectar and pollens belonged to Asteraceae, Balsaminaceae, Brascicaceae, Caprifoliaceae, Cucurbitaceace, Fabaceae, Hypericaceae, Lamiaceae, Liliaceae, Malvaceae, Melastomataceae, Oleaceae, Papaveraceae, Polygonaceae, Rosaceae, Solanaceae and Verbanaceae. The most commonly visited Imatiens scabrida, Solanum tuberosum and Cucurbita sp, belonging to the families Balsiminaceae, Solanaceae and Cucurbitaceae respectively (Fig 4 and fig 5). The hills of Tatopani and Dharapani in Mustang and Manang Districts (fig. 6) had the least 
number of bumblebees, which could be attributed to a lack of flowering host plants for these bees to forage on. The highest frequency of B haemorrhoidalis was recorded to be the foremost common wild Imatiens scabrida flowering host plants on Lower kerauja and Lapu with common visitation of the determined humblebee species. Sunflower, cucumber, and potato were among the cultivated plant species visited by bumblebees for nectar and pollen, while Jasminum hummile (yellow Jasmine) was a common wild herb with a medium level of bumblebee visitation.

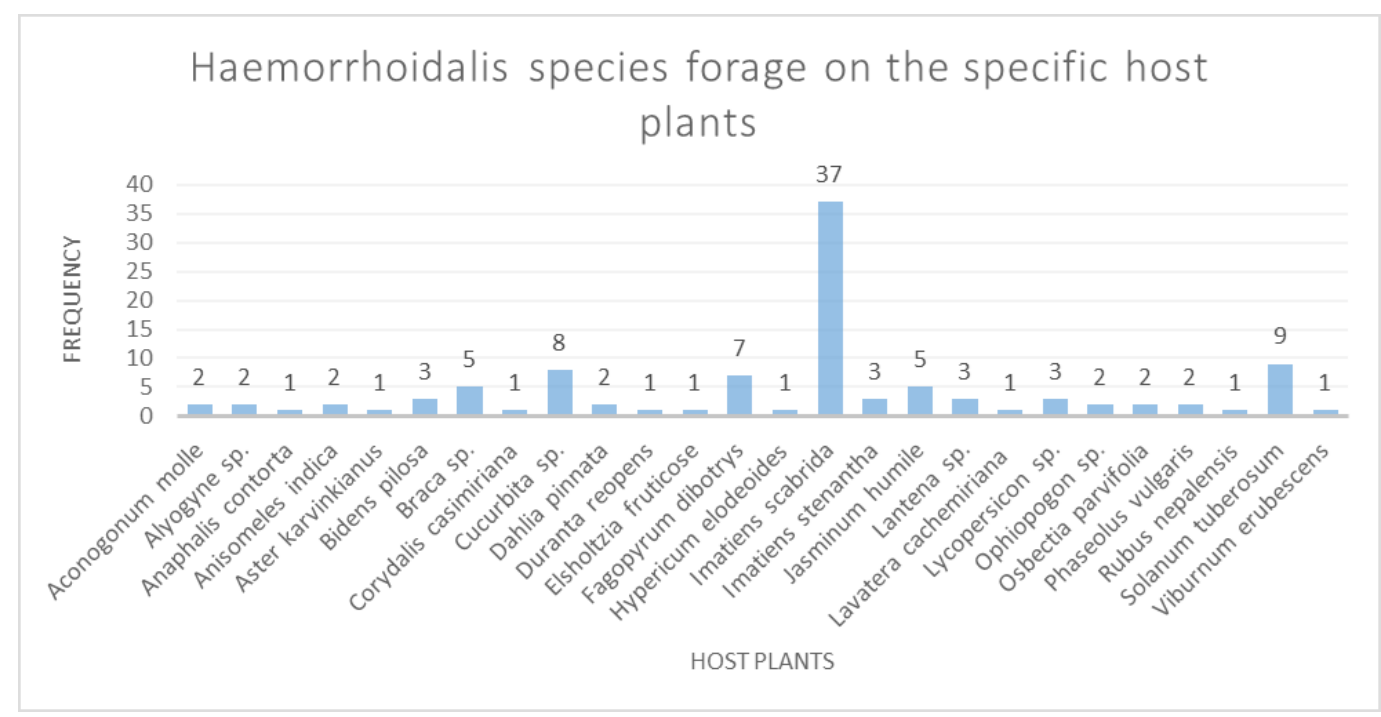

Fig: 4 Foraging frequency of B haemorrhoidalis on specific host plants

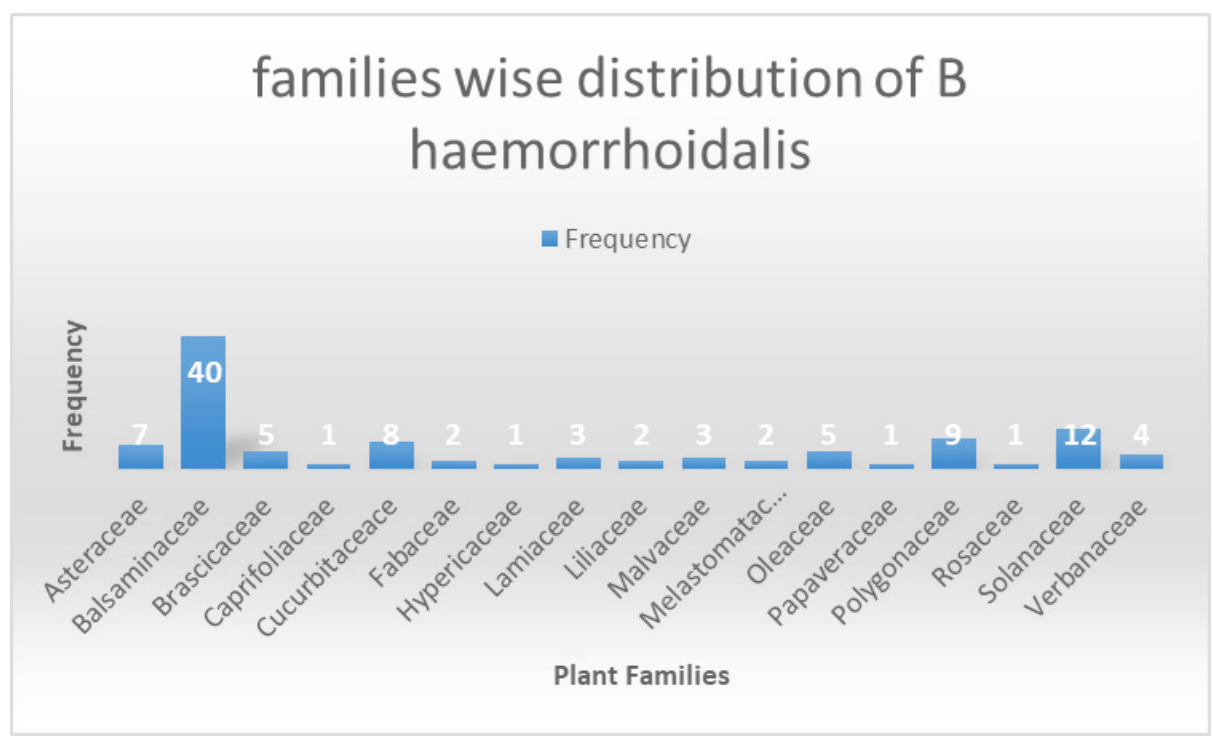

Fig: 5- Foraging of $B$ haemorrhoidalis on families of host plants 


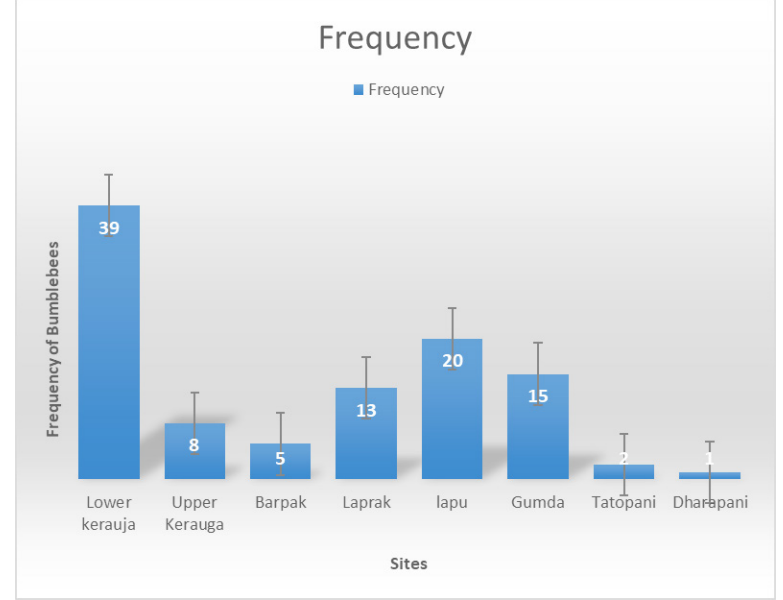

Fig: 6 Site-wise abundance of $B$. haemorrhoidalis in study areas

The thoracic pubescence of $B$. haemorrhoidalis is black, and it has a huge body $(20 \pm 4.4 \mathrm{~mm})$ with long and large wings $(20 \pm 3.2 \mathrm{~mm})$; the forewing is three times longer than the width. Terga1-2 had a bright yellow color, whereas Terga3-5 was an orangered color. The length of antennal segment 3 was 1.5 times that of antennal segment 4 .

\section{Discussion}

In nature, a variety of bee species play an important role in pollination and the survival of plant species. A few bee species have been used for agricultural pollination and expansion in order to meet people's food needs and the economic value of the yields in specific areas. The $B$. haemorrhoidalis was important pollinator of wild as well as agricultural plants of wide range of altitude $(1407-2505 \mathrm{~m}$ asl) and the abundance frequency of this species was also higher lower altitudinal region of mid Himalaya region Nepal. (William et al., 2008) recorded B. haemorrhoidalis at $1000 \mathrm{~m}$ asl in Kasmir India whereas (William et al 2010) recorded this species at the altitude of 850 $\mathrm{m}$ asl, in Nepal and (Saini et al, 2015) recorded at the altitude of (1000-2700 m asl) in India. The abundance frequency of $B$. haemorrhoidalis was correlated to temperature. Foraging of $B$. haemorrhoidlis was found positively correlated with altitude and humidity while negatively correlated with temperature. The study correlates with (Peat and Goulson, 2005) who stated that foraging rates of B. haemorrhoidalis was positively correlated with humidity while temperature did not significantly influence foraging rate. Positive correlation between foraging of bumblebee and humidity is because nectar secretion rates were higher at high humidity (Peat and Goulson, 2005). They also indicated that bumblebees avoid collecting pollen when the foliage is covered in dew or rain-water droplets, which would make grooming pollen into the corbiculae harder. Also, bumblebee's frequency was found positively correlated with altitude which also correlates with (Williams et al., 2010; Streinzer et al., 2019) who has decided species diversity of bees increases with altitude. At contrast with (Hoiss et al., 2012) who 
concluded that species richness and abundance of bees showed a linear decline with increasing altitude because the diversity of species decline linearly with decreasing temperatures. But bumblebees are able to forage at extremely low temperatures (Allen-Wardell et al., 1997; Saini et al., 2012) so their frequency was found negatively correlated with temperature and positively correlated with altitude in the study area. B. haemorrhoidalis had found frequently visiting host plant of family Balsaminaceae, Solanaceae and Polygonaceae. Bumblebee prefers to visit flowers that are larger and more symmetrical and hence enhances pollen transport Moller (1995). So the flowers of the host plants of these families being symmetrical with higher availability of nectar for foraging might be preferred more by bumblebee than the flowers from other rest families. Flowers of balsaminaceae are attractive to pollinators when they are open, since they provide either pollen or nectar, which provides sugar to pollinators (Delaplane and Mayer, 2000). This could be the reason for the greater visitation of bumblebee towards the host plants of balsaminaceae. We also observed that the open flowers of Solanaceae were highly visited by bumblebee, it correlates with the study on Comarum palustre (Rosaceae), in which bumblebees were the main visitors (Somme et al., 2014). Flower aroma is thought to be a crucial long-distance signal for native bees looking for their first floral meal, and it can impact bee behavior, including flower attractiveness (Heinrich et al., 1977; Dotterl et al., 2005). The flowers of Rutaceae are symmetrical and are often sweet-scented which might be the reason that the bumblebees were found to be attracted towards the flowers of the host plants of this family. According to, the bumblebee's species composition is influenced by the landscape context and habitat quality (Carvell et al., 2011).

The agricultural field, forest and grassland was rich in $B$ haemorrhoidalis than the home garden. The diversity and abundance of the bumblebee in the specific habitat is affected by distance between nest and floral resources (Hines and Hendrix, 2005) so it may be the reason for higher diversity and abundance of bumblebee in agricultural land of study area. Also Ockinger and Smith (2007) recorded higher species richness of the bumblebees in the field boundaries within the $100 \mathrm{~m}$ of a semi natural habitat. The reason for high diversity is due to the resources provided by the agricultural land and the presence of the perennials and herbaceous food plants in the in agricultural land. Goulson (2010) revealed the reasons for the highest abundance of bumblebee in the specific habitat is due to the inflow of the foraging bumblebee in the specific habitat from the other areas so the abundance of the bumblebee in agricultural land was higher than the grass land and the human settlement in the study area. The landscape context and the habitat quality influence the species composition of bumblebee as stated by (Carvell et al., 2011).

B. haemorrhoidalis had found repeatedly visiting host plants in the balsaminaceae, solanaceae and cucurbitaceae families. Bumblebees prefer to visit open, more symmetrical blooms, which improves pollen transmission (Moller 1995). Therefore, the flowers of these host plants are symmetrical and have a higher availability of nectar for 
foraging, bumblebees may prefer them over flowers from other rest families. Pollinators are attracted to Imatiens blooms as they open, especially as sources of pollen or nectar, both of which provide a rich source of sugar to pollinators (Delaplane and Mayer, 2000). This could also explain why bumblebees are foraging to Solanum tuberosum host plants in higher numbers. The funnel shaped flowers of cucurbita sps. were also heavily visited by bumblebees, which is consistent with the findings of a previous study on cucurbita sps. Of host plants, in which bumblebees were the primary visitors (Somme et al., 2014). Eugenol and geraniol are frequent floral scent molecules present in beepollinated plants (Dobson 2006; Knudsen et al. 2006), and hence could be employed to influence bumblebee-plant interactions. The flowers of the Balsaminaceae family are symmetrical and frequently sweet-scented, which could explain why bumblebees were drawn to the blooms of the plant.

\section{Conclusion}

B. haemorrhoidalis Smith was mostly observed in the altitudinal range of 1407- 2505 $\mathrm{m}$ asl on agricultural field. As floral resources, this species was found on twenty-seven plants from seventeen different plant families, those floral plants were the main source for provision of nectar and pollens found in wild and agricultural land. The range of the simplest determined species, $B$. haemorrhoidalis became quite numerous and the maximum typically visited plants belonged to circle of relatives Balsaminaceae but, flowers with longer to be had floral resources have been visited greater than quick season flowering.

\section{Acknowledgement}

We are thankful to the University Grand Commission Higher Education for providing funds for the present studies. We are also grateful to Plant Taxonomists (Central Department of Botany, TU) and National Herbarium, Godawari, Lalitpur for plant identification.

\section{References}

Abrol, D. P. (2012). Pollination biology: biodiversity conservation and agricultural production (p. 792). New York: Springer.

Aizen, M. A., Garibaldi, L. A., Cunningham, S. A., \& Klein, A. M. (2008). Long-term global trends in crop yield and production reveal no current pollination shortage but increasing pollinator dependency. Current biology, 18(20), 1572-1575.

Allen-Wardell, G., Bernhardt, P., Bitner, R., Burquez, A., Buchmann, S., Cane, J. et al., (1997). The potential consequences of pollinator declines on the conservation of biodiversity and stability of food crop yields. Conservation Biology, 12(1): 8-17.

An, J., Huang, J., Shao, Y., Zhang, S., Wang, B., Liu, X., Wu, J. Williams, P.H. (2014). The bumblebees of North China (Apidae, Bombus latreille). Zootaxa, 3830(1): 001-089.

Carvell, C., Osborne, J. L., Bourke, A. F. G., Freeman, S. N., Pywell, R. F., \& Heard, M. S. 
(2011). Bumble bee species' responses to a targeted conservation measure depend on landscape context and habitat quality. Ecological Applications, 21(5), 1760-1771.

Couvillon, M. J., Jandt, J. M., Duong, N. H. I., \& Dornhaus, A. (2010). Ontogeny of worker body size distribution in bumble bee (Bombus impatiens) colonies. Ecological Entomology, 35(4), 424-435.

Delaplane, K.S., Mayer, D.F. (2000). Crop Pollination by Bees. Cambridge, U.K.: CABI, 344pp.

Dobson, H.E.M. (2006). Relationship between floral fragrance composition and type of pollinator. In Biology of floral scent. Edited by N. Dudareva and E. Pichersky. CRC Press, Boca Raton, Fla. pp. 147-198.

Dotterl, S., Fussel, U., Jurgens, A. and Aas, G. (2005). 1,4-Dimethoxybenzene, a floral scent compound in willows that attracts an oligolectic bee. J. Chem. Ecol, 31(12): 29932998. doi:10.1007/s10886-005-9152-y. PMID:16258713.

Goulson, D. (2010). Bumblebee, behavior, ecology and conservation (zed). Oxford university press. Oxford

Griffiths, D., \& Robberts, E. J. (1996). Bumble bees as pollinators of glasshouse crops. Bumble bees for pleasure and profit, International Bee Research Organisation, Cardiff, 33-39.

Heinrich, B. (1979). Resource heterogeneity and patterns of movement in foraging bumblebees. Oecologia, 40(3), 235-245. https://doi.org/10.1007/BF00610469.

Hines, H.M. and Hendrix, S.D. (2005). Bumblebees (Hymenoptera:Apidae) diversity and abundances in tall grass prairie patches: effects of local and landscape floral resources. Environmental Entomology, 34: 1477-1484.

Hoiss, B., Krauss, J., Potts, S. G., Roberts, S. and Steffan-Dewenter, I. (2012). Altitude acts as an environmental filter on phylogenetic composition, traits and diversity in bee communities. In: Hoiss, B., Krauss, J., Potts, S. G., Roberts, S. and Steffan-Dewenter, I. eds. Proceedings of Royal Society B: Biological Science, 5th September 2012, Wurzburg, Germany. The Royal Society publishing: 4447-4456.

Klein, A. M., Vaissiere, B. E., Cane, J. H., Steffan-Dewenter, I., Cunningham, S. A., Kremen, C., \& Tscharntke, T. (2007). Importance of pollinators in changing landscapes for world crops. Proceedings of the royal society B: biological sciences, 274(1608), 303-313.

Knudsen, J. T., Eriksson, R., Gershenzon, J., \& Ståhl, B. (2006). Diversity and distribution of floral scent. The botanical review, 72(1), 1-120.

Kwon, Y. J., \& Saeed, S. (2003). Effect of temperature on the foraging activity of Bombus terrestris L.(Hymenoptera: Apidae) on greenhouse hot pepper (Capsicum annuum L.). Applied Entomology and Zoology, 38(3), 275-280.

Miller-Struttmann, N. E., \& Galen, C. (2014). High-altitude multi-taskers: bumble bee food plant use broadens along an altitudinal productivity gradient. Oecologia, 176(4), 10331045.

Moller, A.P. (1995). Bumblebee preference for symmetrical flowers. In: Moller, A.P. ed. Proceeding of the national academy of science, 14 March 1995, United State of America. Evolution: 2288-2292. 
Öckinger, E., \& Smith, H. G. (2007). Semi-natural grasslands as population sources for pollinating insects in agricultural landscapes. Journal of applied ecology, 44(1), 50-59.

Peat, J. and Goulson, D. (2005). Effects of experience and weather on foraging rate and pollen versus nectar collection in the bumblebee, Bombus terrestris. Behavioral Ecology and Sociobiology, 58(2): 152-156.

Saini, M. S., Raina, R. H. and Ghator, H. P. (2015). Indian bumblebee 1st ed. Shiva Offset Press, Dehra Dun, India, 247 pp.

Saini, M.S., Raina, R.H. and Khan, Z. H. (2012). Species diversity of bumblebee (Hymenoptera: Apidae) from different mountain regions of Kashmir Himalayas. Journal of Scientific Research, 4(1): 263-272.

Sinu, P. A., \& Shivanna, K. R. (2007). Pollination ecology of cardamom (Elettaria cardamomum) in the Western Ghats, India. Journal of Tropical Ecology, 23(4), 493-496.

Somme, L., Mayer, C., Jacquemart, A. L. (2014). Multilevel spatial structure impacts on the pollination services of Comarum palustre (Rosaceae). Plosone, 9(6): e99295. Doi:10.1371/journal.pone.0099295.

Streinzer, M., Chakravorty, J., Neumayer, J., Megu, K., Narah, J., Schmitt, T., ... \& Brockmann, A. (2019). Species composition and elevational distribution of bumble bees (Hymenoptera, Apidae, Bombus latreille) in the East Himalaya, Arunachal Pradesh, India. ZooKeys, 851,71 .

Velthuis, H. H., \& Van Doorn, A. (2006). A century of advances in bumblebee domestication and the economic and environmental aspects of its commercialization for pollination. Apidologie, 37(4), 421-451.

Williams, P.H. (1991). The bumblebee of Kashmir Himalaya (Hymenoptera: Apidae:Bombini). Bulletin of British museum (National History, entomology), 60: 1-204.

Williams, P. H., Cameron, S. A., Hines, H. M., Cederberg, B., \& Rasmont, P. (2008). A simplified subgeneric classification of the bumblebees (genus Bombus). Apidologie, 39(1), 46-74.

Williams, P. H., \& Osborne, J. L. (2009). Bumblebee vulnerability and conservation worldwide. Apidologie, 40(3), 367-387.

Williams, P. H., Ito, M., Matsumura, T., \& Kudo, I. (2010). The bumblebees of the Nepal Himalaya (Hymenoptera: Apidae). Insecta matsumurana. New series: journal of the Faculty of Agriculture Hokkaido University, series entomology., 66, 115-151.

YU, W. B., LI, D. Z., \& Wang, H. (2012). Highly efficient pollination by bumblebees ensures seed production in Pedicularis lachnoglossa (Orobanchaceae), an early-flowering Himalayan plant. Journal of Systematics and Evolution, 50(3), 218-226. 